\title{
Cost-effectiveness of diacetylmorphine versus methadone for chronic opioid dependence refractory to treatment
}

\author{
Bohdan Nosyk PhD, Daphne P. Guh MSc, Nicholas J. Bansback PhD, Eugenia Oviedo-Joekes PhD, \\ Suzanne Brissette MD, David C. Marsh MD, Evan Meikleham MSc, Martin T. Schechter MD PhD, \\ Aslam H. Anis PhD
}

\begin{abstract}
Background: Although diacetylmorphine has been proven to be more effective than methadone maintenance treatment for opioid dependence, its direct costs are higher. We compared the cost-effectiveness of diacetylmorphine and methadone maintenance treatment for chronic opioid dependence refractory to treatment.
\end{abstract}

Methods: We constructed a semi-Markov cohort model using data from the North American Opiate Medication Initiative trial, supplemented with administrative data for the province of British Columbia and other published data, to capture the chronic, recurrent nature of opioid dependence. We calculated incremental cost-effectiveness ratios to compare diacetylmorphine and methadone over 1-, 5-, 10-year and lifetime horizons.

Results: Diacetylmorphine was found to be a dominant strategy over methadone maintenance treatment in each of the time horizons. Over a lifetime horizon, our model showed that people receiving methadone gained 7.46 dis- counted quality-adjusted life-years (QALYs) on average (95\% credibility interval $[\mathrm{Cl}] 6.91-8.01)$ and generated a societal cost of $\$ 1.14$ million (95\% Cl \$736 800-\$1.78 million). Those who received diacetylmorphine gained 7.92 discounted QALYs on average (95\% Cl 7.32-8.53) and generated a societal cost of $\$ 1.10$ million (95\% Cl \$724 100-\$1.71 million). Cost savings in the diacetylmorphine cohort were realized primarily because of reductions in the costs related to criminal activity. Probabilistic sensitivity analysis showed that the probability of diacetylmorphine being cost-effective at a willingnessto-pay threshold of \$0 per QALY gained was $76 \%$; the probability was $95 \%$ at a threshold of $\$ 100000$ per QALY gained. Results were confirmed over a range of sensitivity analyses.

Interpretation: Using mathematical modelling to extrapolate results from the North American Opiate Medication Initiative, we found that diacetylmorphine may be more effective and less costly than methadone among people with chronic opioid dependence refractory to treatment.
$\mathrm{O}$ pioid substitution with methadone is the most common treatment of opioid dependence. ${ }^{1-3}$ Participation in a methadone maintenance treatment program has been associated with decreases in illicit drug use, ${ }^{4}$ criminality $^{5}$ and mortality. ${ }^{6.7}$ However, longitudinal studies have shown that most people who receive opioid substitution treatment are unable to abstain from illicit drug use for sustained periods, either switching from treatment to regular opioid use or continuing to use opioids while in treatment..$^{8-13}$ An estimated $15 \%-25 \%$ of the most marginalized methadone clients do not benefit from treatment in terms of sustained abstention from the use of illicit opioids. ${ }^{14}$

The North American Opiate Medication Initiative was a randomized controlled trial that compared supervised, medically prescribed injectable diacetylmorphine and optimized methadone maintenance treatment in people with long-standing opioid dependence and multiple failed treatment attempts with methadone or other forms of treatment. ${ }^{15}$ The trial was conducted in two Canadian cities (Vancouver, British Columbia; and Montréal, Quebec). Both treatment protocols included a comprehensive range of psychosocial services (e.g., addiction counselling, relapse prevention, case management, and individual and group interventions) and primary care services (e.g., testing for bloodborne diseases, provision of HIV treatment, and treatment of acute and chronic physical and mental health complications of substance use) in keeping with Health Canada best practices. ${ }^{16}$ The results of the trial confirmed findings of prior studies showing diacetylmorphine to be more effective than methadone maintenance treatment in retaining opioid-dependent patients in treat-
Competing interests: Suzanne Brissette and David Marsh have received consulting and lecture fees from Schering-Plough. No competing interests declared by the other authors.

This article has been peer reviewed.

Correspondence to: Dr. Aslam H. Anis, aslam.anis@ubc.ca

CMAJ 2012. DOI:10.1503 /cmaj.110669 
ment ${ }^{15,17-20}$ and improving health and social functioning. ${ }^{19,21,22}$ Diacetylmorphine treatment has been proposed to reach a specific population of people with opioid dependence refractory to treatment who are at high risk of adverse health consequences and engagement in criminal activities to acquire the illicit drugs.

For guiding policy-makers, the North American Opiate Medication Initiative alone does not address all the important considerations for decision-making. In addition to political challenges associated with the therapy, ${ }^{23}$ there remains concern over the direct cost of diacetylmorphine over the long term, because it can be as much as 10 times greater than conventional methadone maintenance treatment. ${ }^{21}$ The North American Opiate Medication Initiative was only one year in duration, but a policy to introduce diacetylmorphine might have both positive and negative longerterm implications.

We extrapolated outcomes from the North American Opiate Medication Initiative to estimate the long-term cost-effectiveness of diacetylmorphine versus methadone maintenance treatment for chronic, refractory opioid dependence.

\section{Methods}

\section{Model design}

We developed a decision-analytical model to capture the cycles of treatment, relapse and abstinence observed in long-term observational studies of opioid-dependent individuals. ${ }^{8-13}$ The model type applied was a semi-Markov cohort model. ${ }^{24}$ Because of the chronic, recurrent nature of opioid dependence, we considered time horizons of 1,5 and 10 years as well as the lifetime of the hypothetical cohort to project costs and outcomes over the expected duration of treatment and its effects. A lifetime horizon ensured that all relevant differences in future outcomes of the treatment alternatives would be captured.

Outcome measures, including economic costs (in 2009 Canadian dollars) and quality-adjusted life-years (QALYs), were assessed from the societal perspective, taking into account costs borne by the health care and criminal justice systems, as well as out-of-pocket costs borne by society. Outcomes were reported on a present-value basis, with a $5 \%$ annual discount rate according to Canadian guidelines. ${ }^{25}$ For sensitivity analyses, we considered the perspective of the Ministry of Health, whereby we excluded costs borne by the criminal justice system and out-ofpocket costs, and we considered the perspective of the third-party payer, whereby we excluded out-of-pocket costs. All analyses conformed to guidelines on cost-effectiveness analyses conducted alongside clinical trials and economic modelling. ${ }^{25-27}$ Analyses were performed using R Project software (www.r-project.org).

Our primary analysis was based on a hypothetical cohort of patients assigned the baseline characteristics of the participants in the North American Opiate Medication Initiative - assumed to be representative of the North American population that diacetylmorphine treatment would reach. Detailed inclusion and exclusion criteria and baseline characteristics of the study participants have been published previously. ${ }^{23,28}$ In brief, at baseline, the study participants were 25 years or older, with regular opioid injection, a minimum five-year history of opioid use, and at least two previous attempts at substitution treatment for opioid dependence. The average age of the participants was 39.7 years, and $61.4 \%$ were men. The baseline prevalence of HIV infection was $9.6 \%$ and of hepatitis $\mathrm{C}$ virus infection $62.9 \%{ }^{23}$

Health states in our model ${ }^{29}$ included treatment (diacetylmorphine or methadone maintenance treatment), relapse (defined by opioid use outside of treatment), abstinence from opioids and death. Patients in the model belonged to one of two cohorts (diacetylmorphine or methadone maintenance treatment), and all patients entered the model in a treatment state, which was assumed to be their third attempt at treatment. The dynamics of the cohort model are shown in Figure 1. A new treatment cycle was defined as one beginning each time a patient re-entered treatment through relapse. Transitions between health states could occur every 30 days.

\section{Model parameters}

Given the unique design of the North American Opiate Medication Initiative and the breadth of data collected on participants, we derived model parameters from the trial data where possible. When trial data were not available to populate model parameters, we conducted literature searches; published data on Canadian cohorts or local data sources were used preferentially. Further details are provided in Appendix 1 (available at www.cmaj.ca/lookup/suppl/doi:10.1503 /cmaj.110669/-/DC1).

\section{Transitions between states}

We estimated the durations of periods of treatment, relapse and abstinence using Weibull regression models based on trial data from the North American Opiate Medication Initiative and supplemented with external data sources; the probability of transitioning was a function of the time spent in the respective state. ${ }^{29,30}$ Subsequent episodes of treatment and relapse differed in 
duration according to findings from a prior analysis of an 11-year population-level study of methadone recipients in British Columbia. ${ }^{31}$ After adjusting for a number of individual and treatment-related factors, the authors found that, among those who had multiple treatment episodes, later episodes tended to last longer.

All probabilities of transitions between health states were conditional on survival. Age- and sex-specific death rates for the general Canadian population were used to assign probabilities of transition to death for HIV-negative individuals in the abstinence state of the model..$^{32}$ The estimates of mortality were then multiplied by standardized mortality ratios for untreated opioid users $^{33}$ and for those given diacetylmorphine; ${ }^{34}$ for individuals given methadone, the estimates were calculated using the relative risk of death in methadone maintenance treatment versus no treatment. ${ }^{6}$ Because direct estimates of mortality among people with refractory opioid dependence in methadone maintenance treatment were not

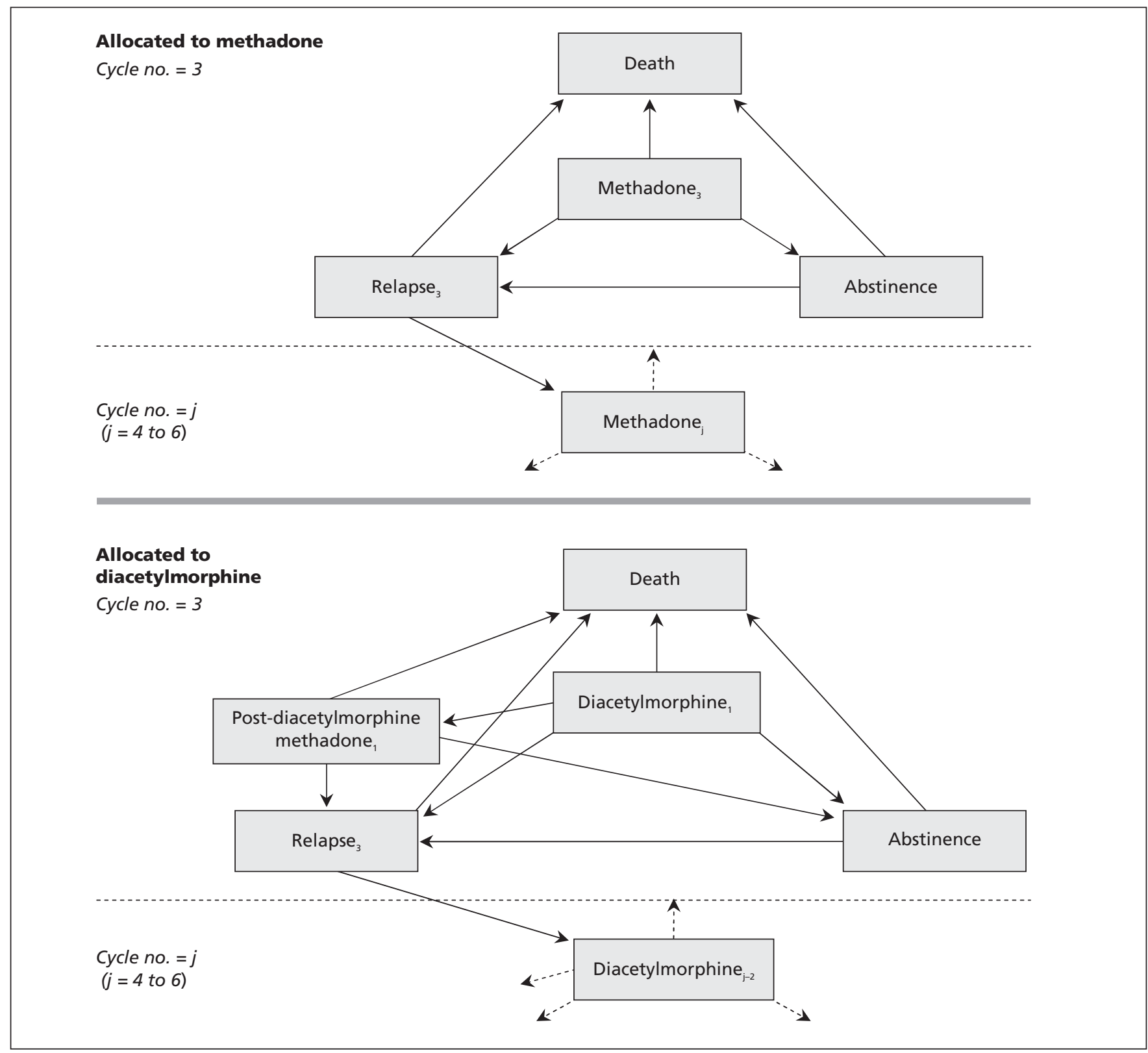

Figure 1: Dynamics of the cohort model. All patients entered the model in a treatment state (diacetylmorphine or methadone maintenance treatment), which was assumed to be their third attempt at treatment of opioid dependence. Patients assigned to the diacetylmorphine cohort could transition to abstinence, relapse, death or methadone treatment (denoted as "post-diacetylmorphine methadone"). From the methadone or the post-diacetylmorphine methadone state, patients could transition to abstinence, relapse or death. From the abstinence state, patients could transition to relapse or death. From the relapse state, patients could transition to death or to a new treatment episode and a new cycle of health states. The probabilities of transitioning from the treatment and relapse health states differed according to the cycle number. 
available, we used alternative estimates for the methadone and relapse states in the sensitivity analyses. ${ }^{35,36}$

\section{HIV seroconversion}

The probability of HIV seroconversion was a function of treatment status, frequency of heroin injection, and unprotected sexual contact. ${ }^{37,38}$ Seroconversion could occur at any stage in the model and was independent of transitioning between states of treatment, relapse and abstinence.

\section{Direct and indirect costs}

Patients accumulated costs as a result of opioid substitution treatment, drug treatments for HIV and hepatitis $\mathrm{C}$ virus infection, other health care use, self-reported criminal activity and criminal charges within each 30-day period in the simulation model. The costs related to criminal activity included costs borne by the criminal justice system as well as out-of-pocket costs resulting from criminal victimization. Fully allocated treatment costs of methadone and diacetylmorphine, including costs of medication, human resources and overhead, were sourced from the North American Opiate Medication Initiative. Costs of drug treatment for HIV and hepatitis $\mathrm{C}$ virus infection were estimated based on the estimated proportion of infected patients receiving treatment.

On the basis of daily treatment records, participants in the North American Opiate Medication Initiative were classified as being in treatment (diacetylmorphine or methadone maintenance treatment) or in relapse within each month. Estimates of costs related to each health state were derived from generalized linear mixed-effects regression models that controlled for age, sex and HIV status to account for heterogeneity of participants and allowed for changes in costs over time. We also used treatment-specific regression models (diacetylmorphine v. methadone maintenance treatment) to estimate costs. The costs of health resource use, criminal activity and criminal charges, although uniformly lower in the diacetylmorphine cohort than in the methadone cohort, did not differ significantly between the cohorts.

The frequency of other health resource use and the frequency of crime without criminal charges (i.e., self-reported crime) were based on data from the North American Opiate Medication Initiative. Data from provincial court records were extracted for each trial participant and used to represent the frequency of criminal charges.

All costs were calculated by multiplying resource use by respective unit costs.

\section{Quality-adjusted life-years}

We calculated the number of QALYs gained in the treatment and relapse states using estimates of indirect utility measured by the Euroqol EQ$5 D^{39,40}$ with United States preference weights, ${ }^{41}$ previously shown to be the appropriate utility measure for the North American Opiate Medication Initiative study population. ${ }^{42}$ We calculated health utility estimates for the methadone maintenance treatment, diacetylmorphine (both treatment-nonspecific and treatment-specific) and relapse states from trial data using generalized linear mixed-effects regression.

\section{Incremental cost-effectiveness analysis and uncertainty analysis}

We expressed the comparative value of diacetylmorphine versus methadone maintenance treatment using the incremental cost-effectiveness ratio, interpreted as the incremental cost per QALY gained from making diacetylmorphine available as a treatment for opioid dependence. A dominant strategy is one whose cost is lower and effectiveness (measured as QALYs in our analysis) is higher than the comparator's. Because the interpretation of negative incremental costeffectiveness ratios is ambiguous ${ }^{43}$ these instances were indicated as "cost-saving" in the presentation of results.

We evaluated the robustness of the results with changes in model inputs, using probabilistic and one-way sensitivity analyses. Probabilistic sensitivity analysis was executed via Monte Carlo simulation, where parameter estimates were sampled from probability distributions described in Table 1. One-way sensitivity analyses were performed to determine the effect of varying key assumptions and parameters in the model, including the maximum number of treatment episodes with diacetylmorphine, treatment retention beyond the initial (third) attempt, patient age at model entry, costs related to criminal activity during relapse and other alternative scenarios.

\section{Results}

Diacetylmorphine was found to be a dominant strategy over methadone maintenance treatment in each time horizon studied (Table 2). Over a lifetime horizon, people in the methadone cohort lived 14.54 years on average following entry into the model, spending 8.79 years $(60 \%$ of their remaining life) in treatment and 5.52 years in relapse. They accumulated 7.46 discounted QALYs and generated a societal cost of $\$ 1.14$ million. People in the diacetylmorphine cohort lived 15.45 years on average, spending 10.41 years $(67 \%$ of their remaining life) in treatment (2.34 years of which was in post- 
Table 1: Estimates for model parameters in cost-effectiveness analysis of diacetylmorphine versus methadone maintenance treatment for chronic, refractory opioid dependence (part 1 of 2)

\begin{tabular}{|c|c|c|c|}
\hline Parameter & Estimate & Distribution & Source \\
\hline \multicolumn{4}{|l|}{ Probability of health state transition } \\
\hline \multicolumn{4}{|l|}{ Methadone state } \\
\hline Remain in methadone state* & $\lambda=0.114, \gamma=0.643$ & Weibull & BC MMTOS \\
\hline Multiplier: Episode $4 \dagger$ & $0.923(0.033)$ & Normal & BC MMTOS \\
\hline Multiplier: Episode 5 & $0.965(0.042)$ & Normal & \\
\hline Multiplier: Episode 6 & $0.952(0.041)$ & Normal & \\
\hline Transition to relapse state & $95.9 \%$ & Beta & BC MMTOS \\
\hline Transition to abstinence state & $4.1 \%$ & & \\
\hline \multicolumn{4}{|l|}{ Diacetylmorphine state } \\
\hline Remain in diacetylmorphine state* & $\lambda=0.061, \gamma=0.761$ & Weibull & NAOMI \\
\hline Multiplier: Episode $4 \ddagger$ & $0.923(0.033)$ & Normal & BC MMTOS \\
\hline Multiplier: Episode 5 & $0.965(0.042)$ & Normal & \\
\hline Multiplier: Episode 6 & $0.952(0.041)$ & Normal & \\
\hline Transition to relapse state§ & $37.0 \%$ & Dirichlet & Rehm et al. ${ }^{44}$ \\
\hline Transition to abstinence state & $22.4 \%$ & & \\
\hline Transition to methadone state & $40.7 \%$ & & \\
\hline \multicolumn{4}{|l|}{ Relapse state } \\
\hline Remain in relapse state* & $\lambda=0.091, \gamma=0.672$ & Weibull & BC MMTOS \\
\hline Multiplier: Episode 4 & $1.220(0.048)$ & Normal & BC MMTOS \\
\hline Multiplier: Episode 5 & $1.350(0.060)$ & Normal & \\
\hline Multiplier: Episode 6 & $1.442(0.056)$ & Normal & \\
\hline Transition to treatment state & 1 & Fixed & \\
\hline \multicolumn{4}{|l|}{ Abstinence state } \\
\hline Remain in abstinence state* & $\lambda=0.089, \gamma=0.797$ & Weibull & Termorshuizen et al. $^{12}$ \\
\hline Transition to relapse state & 1 & Fixed & \\
\hline \multicolumn{4}{|l|}{ Transition to death? } \\
\hline Abstinence state, HIV negative & See Appendix 1, Table A1 & Fixed & Statistics Canada ${ }^{32}$ \\
\hline $\begin{array}{l}\text { Abstinence state, HIV positive, standardized } \\
\text { mortality ratio, mean (SD) }\end{array}$ & $1.47(1.07,2.01)$ & Normal & $\operatorname{ATCC}^{45}$ \\
\hline Relapse state, standardized mortality ratio, mean (SD) & $30.063(3.169)$ & Normal & Spittal et al. ${ }^{33}$ \\
\hline Methadone state, relative risk, mean (SD) & $0.350(0.087)$ & Normal & Caplehorn et al. ${ }^{6}$ \\
\hline $\begin{array}{l}\text { Diacetylmorphine state, standardized mortality } \\
\text { ratio, mean (SD) }\end{array}$ & $9.70(0.17)$ & Normal & Rehm et al..$^{34}$ \\
\hline \multicolumn{4}{|l|}{ HIV seroconversion** } \\
\hline Treatment state, mean (SD) & $0.0028(0.0010)$ & Beta & Bayoumi et al. ${ }^{38}$ \\
\hline Relapse state, mean (SD) & $0.0364(0.0146)$ & Beta & \\
\hline Abstinence state, mean (SD) & $0.0007(0.0001)$ & Beta & \\
\hline \multicolumn{4}{|l|}{ QALYstt } \\
\hline Methadone or diacetylmorphine state & 0.852 & MVN & NAOMI \\
\hline Relapse state & 0.750 & MVN & NAOMI \\
\hline Abstinence state, HIV negative & See Appendix 1, Table A15 & Beta & Johnson et al. ${ }^{46}$ \\
\hline Abstinence state, HIV positive, mean (SD) & $0.77(0.19)$ & Beta & Anis et al. ${ }^{47}$ \\
\hline \multicolumn{4}{|l|}{ Monthly costs, $\neq \pm$ Can\$ } \\
\hline \multicolumn{4}{|l|}{ Drug treatment } \\
\hline Methadone, mean (SD) & 329.38 (24.46) & Normal & NAOMI, BC PNET \\
\hline Diacetylmorphine, mean (SD) & $1415.21(25.68)$ & Normal & NAOMI \\
\hline HIV infection & 28.30 & Fixed & $\begin{array}{l}\text { Wood et al. }{ }^{48} \text { and } \\
\text { Krentz et al. }{ }^{49}\end{array}$ \\
\hline Hepatitis $\mathrm{C}$ virus infection & 673.82 & Fixed & Butt et al. ${ }^{50}$ and BC PNET \\
\hline
\end{tabular}


Table 1: Estimates for model parameters in cost-effectiveness analysis of diacetylmorphine versus methadone maintenance treatment for chronic, refractory opioid dependence (part 2 of 2)

\begin{tabular}{|c|c|c|c|}
\hline Parameter & Estimate & Distribution & Source \\
\hline \multicolumn{4}{|l|}{ Methadone or diacetylmorphine state§§ } \\
\hline Health resource utilization, HIV positive & 72.10 & MVN & NAOMI \\
\hline Criminal involvement & 950.52 & MVN & NAOMI \\
\hline Criminal charges & 398.82 & MVN & NAOMI \\
\hline \multicolumn{4}{|l|}{ Relapse state§§ } \\
\hline Health resource utilization, HIV positive & 695.98 & MVN & NAOMI \\
\hline Criminal involvement & 8981.28 & MVN & NAOMI \\
\hline Criminal charges & 590.05 & MVN & NAOMI \\
\hline
\end{tabular}

Note: $\mathrm{ATCC}=$ Antiretroviral Therapy Cohort Collaboration, BC MMTOS $=$ British Columbia Methadone Maintenance Treatment Outcome Study, BC PNET $=$ British Columbia PharmaNet database, MVN = multivariate normal, NAOMI = North American Opiate Medication Initiative, QALY = quality-adjusted life-year, SD $=$ standard deviation. Appendix 1 is available at www.cmaj.ca/lookup/suppl/doi:10.1503/cmaj.110669//IDC1.

*Parameter estimates provided for the time to discontinuation of each health state represent the shape $(\gamma)$ and scale $(\lambda)$ parameters of the Weibull distribution.

From estimated survival functions, at 12 months, the probability of remaining in methadone treatment was about $47 \%, 68 \%$ in diacetylmorphine treatment, $62 \%$ in relapse and $52 \%$ in abstinence.

tDerived from Cox proportional hazards frailty models on successive episodes of treatment and relapse. ${ }^{36}$ All multipliers presented are hazard ratios and corresponding standard errors.

\#Change in duration of successive diacetylmorphine episodes was assumed to be equivalent to change in duration of successive methadone episodes.

§Included transition to methadone state $(n=379)$ and other treatment $(n=28)$ among all participants alive at the end of follow-up and not lost to follow-up ( $n=1001)$. IS Sex-specific estimates used in the model for HIV-negative individuals in the abstinence state are presented in Appendix Table A7. For monthly probabilities of death in the abstinence-HIV positive, diacetylmorphine and relapse states, we multiplied base probabilities by state-specific standardized mortality ratios; for monthly probabilities of death in the methadone state, we multiplied the base probabilities by standardized mortality ratios and relative risks.

**Calculations and specific references for state-specific HIV seroconversion are shown in Appendix Table A5.

t+Calculations are shown in section A2.3 in Appendix Tables A13-A16.

¥¥Calculations are shown in section A2.2 in Appendix Tables A8-A14.

$\S \S F o r$ all costs related to health resource use, criminal involvement and criminal charges, trial-based data on utilization/frequency of events was multiplied by unit costs from several sources, detailed in Appendix Table A8. Presented state-specific costs are estimated mean values, given the mean age, HIV status and sex mix of participants in the NAOMI study. Costs were a function of each of these parameters in the cohort simulation model.

Table 2: Estimated cost-effectiveness of diacetylmorphine compared with methadone in the treatment of chronic, refractory opioid dependence

\begin{tabular}{|c|c|c|c|c|c|c|}
\hline \multirow[b]{2}{*}{$\begin{array}{l}\text { Time horizon; } \\
\text { treatment }\end{array}$} & \multirow[b]{2}{*}{$\begin{array}{c}\text { Cost, Can } \$ \times 1000 \\
\text { mean }(95 \% \mathrm{Cl})\end{array}$} & \multicolumn{3}{|c|}{ Cost component, $\%$ of total } & \multirow[b]{2}{*}{$\begin{array}{c}\text { QALYs, } \\
\text { mean }(95 \% \mathrm{Cl})\end{array}$} & \multirow{2}{*}{$\begin{array}{c}\text { Incremental } \\
\text { cost-effectiveness ratio } \\
\text { Can } \$ \times 1000 \text { per QALY } \\
\text { gained, mean }(95 \% \mathrm{Cl})\end{array}$} \\
\hline & & Treatment & $\begin{array}{l}\text { Health } \\
\text { resources } \\
\text { utilization }\end{array}$ & $\begin{array}{l}\text { Criminal } \\
\text { activity and } \\
\text { charges }\end{array}$ & & \\
\hline \multicolumn{7}{|l|}{1 year } \\
\hline Diacetylmorphine & $85.9 \quad(63.8-116.7)$ & 17.7 & 4.2 & 78.1 & $0.86(0.83-0.90)$ & CS (CS-485.8) \\
\hline \multicolumn{7}{|l|}{5 years } \\
\hline Diacetylmorphine & $387.7(293.4-511.6)$ & 12.3 & 8.2 & 79.5 & $3.43(3.26-3.59)$ & CS (CS-103.4) \\
\hline Methadone & $418.3(297.0-579.0)$ & 2.5 & 11.2 & 86.2 & $3.32(3.14-3.47)$ & \\
\hline \multicolumn{7}{|l|}{10 years } \\
\hline Diacetylmorphine & $696.0(504.9-960.0)$ & 10.4 & 11.1 & 78.5 & $5.61(5.29-5.90)$ & CS (CS-78.2) \\
\hline Methadone & $1137.6(736.8-1776.5)$ & 2.1 & 16.7 & 81.2 & $7.46(6.91-8.01)$ & \\
\hline
\end{tabular}

diacetylmorphine methadone treatment) and 4.05 years in relapse. They accumulated 7.92 discounted QALYs and generated a societal cost of $\$ 1.10$ million. Based on these findings in the baseline model, over a lifetime horizon the pro- vision of diacetylmorphine in the hypothetical cohort provided greater incremental health benefits and reduced the total costs to society compared with methadone maintenance treatment.

Probabilistic sensitivity analysis found di- 
acetylmorphine to be the preferred treatment option for short- and longer-time horizons and a wide range of threshold values of societal willingness to pay (Figure 2 shows the findings for the lifetime horizon). Small differences in QALYs gained after one year led to large credibility intervals on incremental cost-effectiveness ratios on a one-year time horizon.

The costs of drug treatment comprised a larger percentage of overall costs in the diacetylmorphine cohort than in the methadone cohort (Table 2). The percentage decreased with longer time horizons. The component of overall costs attributed to health resource utilization increased over time in both cohorts. The costs related to criminal activity formed the largest component by a wide margin in both cohorts, accounting for $77 \%$ of overall costs in the diacetylmorphine cohort and $81 \%$ in the methadone cohort over a lifetime horizon.

\section{Sensitivity analyses}

We performed sensitivity analyses of the costs of criminal activity during relapse, and the time to discontinuation of diacetylmorphine treatment, to determine the threshold at which the decision to fund treatment changes. For diacetylmorphine to be deemed not costeffective at a threshold of $\$ 100000$ per QALY gained, the costs of criminal activity during relapse would have to be nearly $60 \%$ lower than the costs used in the baseline model (Figure 3). Conversely, an increase in these costs increased the increment in total costs accrued by the methadone cohort versus the diacetylmorphine cohort because of the greater time spent in relapse in the methadone cohort. Decreasing the estimated time in diacetylmorphine treatment was associated with increased costs and decreased QALYs (Figure 4A). However, given that participants in the North American Opiate Medication Initiative who received diacetylmorphine had a greater probability of achieving a better outcome (i.e., not relapsing) following discontinuation of treatment than participants in the methadone cohort had, at least a $60 \%$ decrease in the duration of diacetylmorphine treatment episodes would be required before the diacetylmorphine cohort gained fewer QALYs than the methadone cohort (Figure 4B).

Diacetylmorphine remained cost-saving in virtually all of the other sensitivity analyses (Table 3 and Appendix 1). From a Ministry of Health perspective (in which crime-related costs and out-ofpocket costs were excluded), diacetylmorphine was no longer cost-saving, but it remained costeffective at an incremental cost-effectiveness ratio of $\$ 85600$ per QALY gained (Table 3).

\section{Interpretation}

Using mathematical modelling to extrapolate results from the North American Opiate Medication Initiative, we found that diacetylmorphine may be more effective and less costly than methadone maintenance treatment for chronic, refractory opioid dependence. The baseline

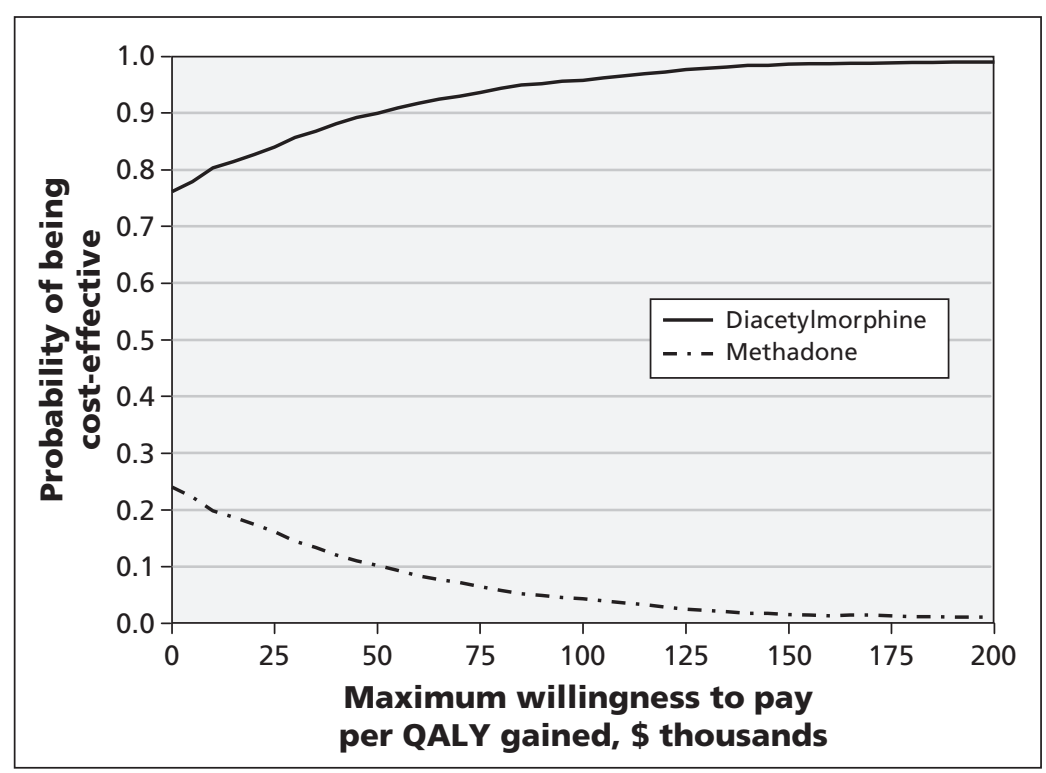

Figure 2: Cost-effectiveness acceptability curve for the lifetime horizon, plotting the probability that either treatment strategy (diacetylmorphine or methadone) would be cost-effective for a range of threshold values of societal willingness to pay to gain one quality-adjusted life-year (QALY). The probability of diacetylmorphine being cost-effective at a threshold of \$0 per QALY gained (costsaving) is $76 \%$. At a societal willingness to pay of $\$ 100000$ per QALY gained, diacetylmorphine is the cost-effective treatment option with $95 \%$ certainty, whereas methadone is the cost-effective treatment option with $5 \%$ certainty.

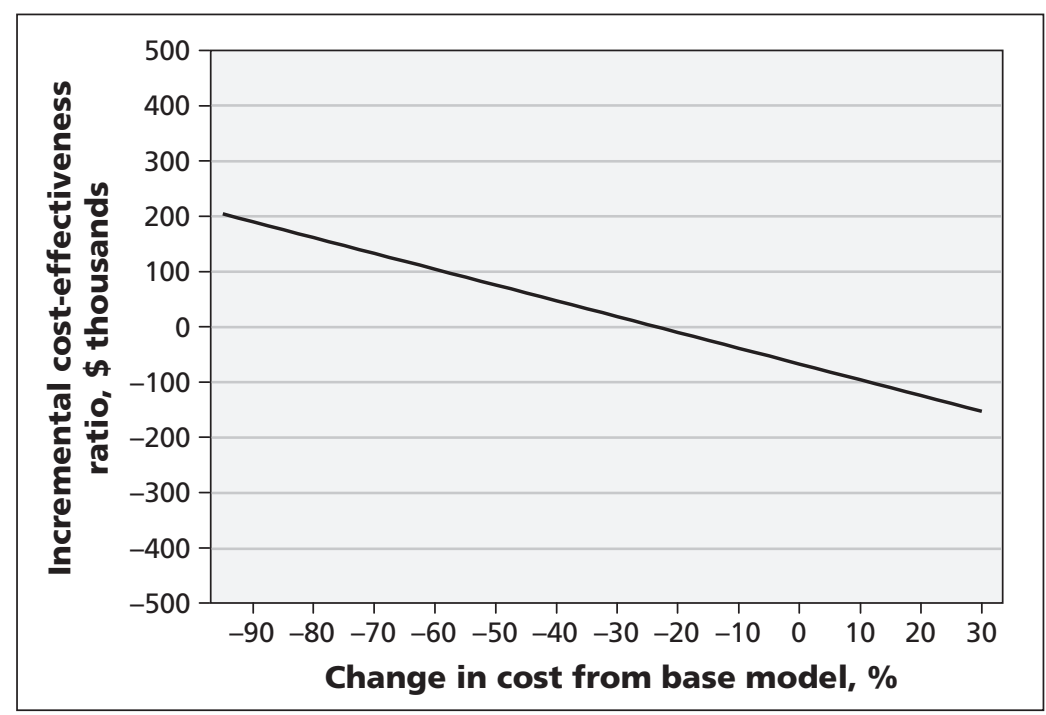

Figure 3: One-way sensitivity analysis of the effect of changes in the monthly costs related to criminal activity during relapse from values used in the baseline model on the incremental cost-effectiveness ratio of diacetylmorphine versus methadone maintenance treatment. A decrease in monthly costs of about $20 \%$, applied to both treatment strategies, would result in an incremental costeffectiveness ratio greater than zero (higher costs and higher quality-adjusted life-years) for diacetylmorphine v. methadone. 
model indicated that diacetylmorphine would decrease societal costs, largely by reducing costs associated with crime, and would increase both the duration and quality of life of treatment recipients. Because opioid users commit less crime and have lower rates of health care use and death while in treatment, ${ }^{7,51,52}$ the benefits in cost and health utility attributable to diacetylmorphine stemmed chiefly from its capacity to retain patients in treatment for longer periods than with methadone maintenance treatment.

From a societal perspective, diacetylmorphine was estimated to be cost-effective for a wide range of values of societal willingness to pay. We also presented the narrower perspective of the

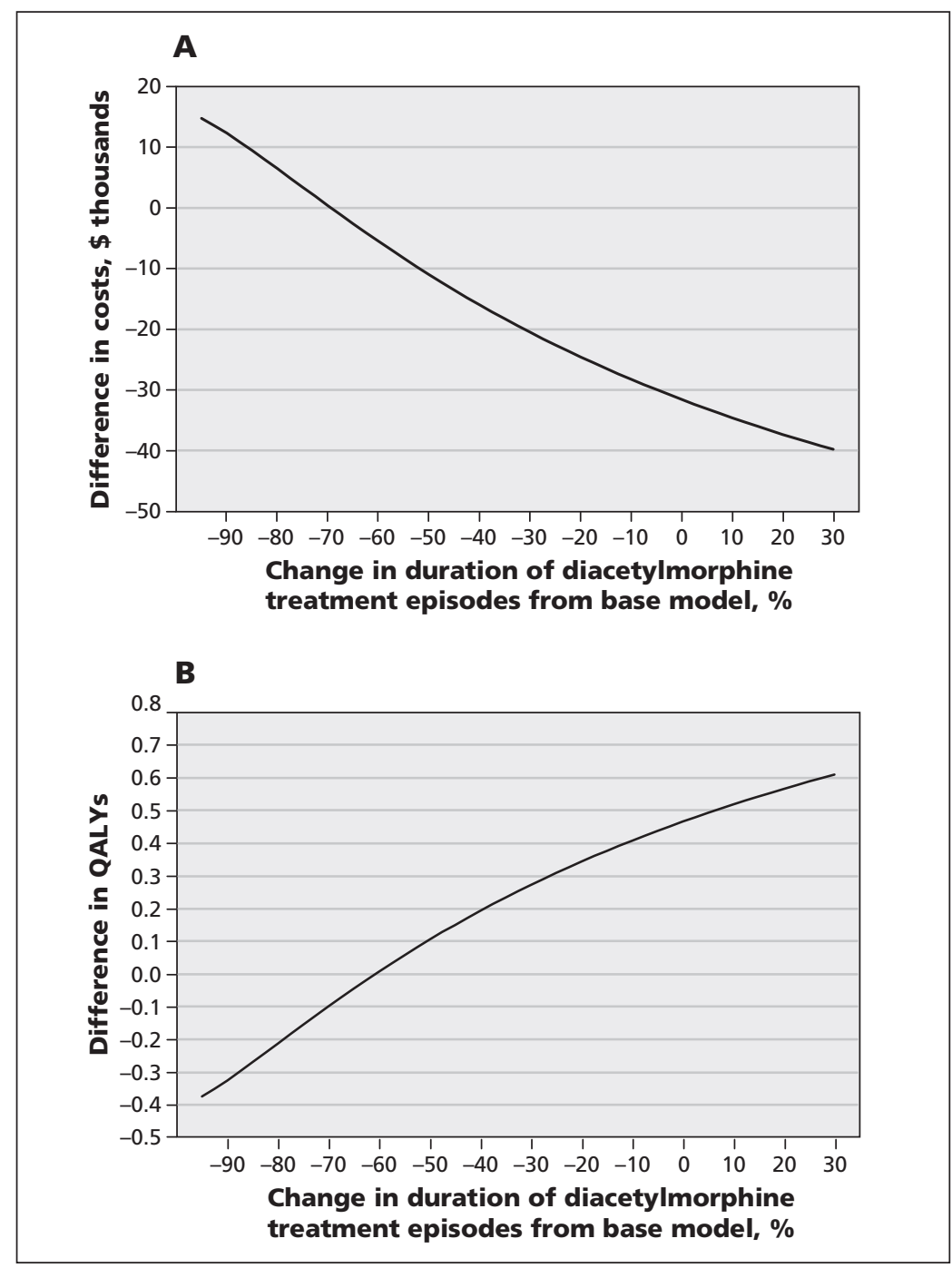

Figure 4: One-way sensitivity analyses of the effect of changes in the duration of diacetylmorphine treatment episodes from values used in the baseline model (deterministic analysis) on (A) costs of diacetylmorphine (v. methadone) treatment and (B) quality-adjusted life-years (QALYs). Use of the average duration of a diacetylmorphine treatment episode in the baseline model resulted in an incremental cost of about $-\$ 32000$ and 0.47 incremental QALYs. Decreasing the average duration of treatment by $30 \%$ would result in diminished incremental costs (from $-\$ 32000$ to $-\$ 20000$ ) and diminished incremental QALYs (from 0.47 to 0.28 ).
Ministry of Health (exclusion of costs related to criminal activity and out-of-pocket costs). However, decision-making based only on this perspective is akin to a silo-based approach to allocating government funds and is biased against health innovations that provide benefits beyond the scope of the health care system.

Our results on the cost-effectiveness of diacetylmorphine are consistent with those of an economic analysis based on data from two Dutch heroin-assisted treatment trials, ${ }^{21}$ despite differences in the design of the Dutch trials and the North American Opiate Medication Initiative, and the time horizon and analytic design of the economic analyses.

The Dutch trials compared methadone maintenance treatment with a combination of methadone and diacetylmorphine (prescribed concurrently), which changed the profiles of health utility and health resource use. Furthermore, participants in the Dutch trials were recruited from methadone maintenance programs, whereas participants in the North American Opiate Medication Initiative had to have been out of treatment for at least six months before trial entry. We considered a range of time horizons, using external parameters where necessary to extrapolate results to longer time horizons. The other economic analysis used trial data exclusively and focused only on a 12-month study period. The consistency in results between our analysis and the analysis of the Dutch trials appears to be due primarily to the advantages diacetylmorphine provides in retaining individuals in treatment.

We believe a lifetime horizon is the most appropriate period for evaluating treatments of chronic, recurrent diseases such as opioid dependence, because treatment is available indefinitely in practice and will have a long-term impact. The key outcomes, such as progressing to a drug-free state or death, would likely not be realized within the 12-month period of the North American Opiate Medication Initiative.

\section{Limitations}

Our study was not without limitations. First, data on opioid users reaching state of abstinence were scarce, as were data on the long-term patterns of treatment and relapse among those receiving diacetylmorphine. For the former, results were not sensitive to differences in assumptions on health utility valuations for individuals reaching a state of abstinence. For the latter, results were presented at short- and longer-time horizons, and extensive sensitivity analyses confirmed the robustness of the results from the baseline model.

Second, the cost of incarceration as a result of 
Table 3: Results of sensitivity analyses of the cost-effectiveness of diacetylmorphine compared with methadone in the treatment of refractory opioid dependence over a lifetime horizon (part 1 of 2)

\begin{tabular}{|c|c|c|c|c|c|c|}
\hline Analysis; treatment & $\begin{array}{l}\text { Cost, Can } \$ \times 1000 \\
\text { mean }(95 \% \mathrm{Cl})\end{array}$ & \multicolumn{3}{|c|}{ Cost component, $\%$ total } & $\begin{array}{l}\text { QALYs, } \\
\text { mean }(95 \% \mathrm{Cl})\end{array}$ & $\begin{array}{l}\text { Incremental } \\
\text { cost-effectiveness ratio, } \\
\text { Can } \$ \times 1000 \text { per QALY } \\
\text { gained, mean }(95 \% \mathrm{Cl})\end{array}$ \\
\hline \multicolumn{7}{|c|}{ Third-party payer perspective* } \\
\hline Diacetylmorphine & $971.5(642.1-1489.9)$ & 10.5 & 15.7 & 73.8 & $7.92 \quad(7.32-8.53)$ & CS (CS-129.9) \\
\hline \multicolumn{7}{|l|}{$\begin{array}{l}\text { Ministry of Health } \\
\text { perspectivet }\end{array}$} \\
\hline Diacetylmorphine & $247.6(170.8-401.9)$ & 41.1 & 58.9 & - & 7.92 (7.32-8.53) & 85.6 (CS-363.1) \\
\hline Methadone & $208.0(113.9-386.3)$ & 12.1 & 87.9 & - & $7.46 \quad(6.91-8.01)$ & \\
\hline \multicolumn{7}{|c|}{$\begin{array}{l}\text { Diacetylmorphine not } \\
\text { available after initial relapse }\end{array}$} \\
\hline Diacetylmorphine & $1105.3(730.7-1732.7)$ & 8.8 & 14.5 & 76.7 & $7.81 \quad(7.21-8.43)$ & CS (CS-105.6) \\
\hline Methadone & $1155.4(748.2-1825.0)$ & 1.9 & 17.3 & 80.8 & 7.29 (6.77-7.81) & \\
\hline \multicolumn{7}{|c|}{$\begin{array}{l}\text { Time to discontinuation of } \\
\text { relapse for diacetylmorphine } \\
\text { from NAOMI trial data }\end{array}$} \\
\hline Diacetylmorphine & $1018.7(673.4-1629.1)$ & 13.0 & 10.8 & 76.1 & $8.58 \quad(7.87-9.29)$ & CS (CS-847.5) \\
\hline Methadone & $1042.6(664.1-1678.3)$ & 3.1 & 14.0 & 82.9 & $8.18 \quad(7.32-9.09)$ & \\
\hline \multicolumn{7}{|c|}{$\begin{array}{l}\text { Time to discontinuation of } \\
\text { post-diacetylmorphine methadone for } \\
\text { diacetylmorphine from NAOMI trial data }\end{array}$} \\
\hline \multicolumn{7}{|c|}{$\begin{array}{l}\text { Exponential distributions set for } \\
\text { time to discontinuation curves }\end{array}$} \\
\hline \multicolumn{7}{|c|}{$\begin{array}{l}\text { Probability of HIV } \\
\text { seroconversion set to zero }\end{array}$} \\
\hline Diacetylmorphine & $1017.9(652.7-1624.6)$ & 10.0 & 7.3 & 82.7 & $7.94 \quad(7.33-8.54)$ & CS (CS-147.1) \\
\hline Methadone & $1039.3(647.1-1692.6)$ & 2.3 & 8.6 & 89.1 & $7.46 \quad(6.91-8.02)$ & \\
\hline \multicolumn{7}{|l|}{ Discount rate $0 \%$} \\
\hline Diacetylmorphine & $1802.9(1114.6-3040.9)$ & 8.6 & 15.8 & 75.5 & $12.16(11.04-13.37)$ & CS (CS-223.4) \\
\hline Methadone & $1837.5(1128.1-3112.3)$ & 2.0 & 18.3 & 79.7 & $11.29(10.27-12.37)$ & \\
\hline \multicolumn{7}{|l|}{ Discount rate $3 \%$} \\
\hline Diacetylmorphine & $1317.7(850.0-2116.7)$ & 9.0 & 14.7 & 76.2 & $9.28 \quad(8.52-10.07)$ & CS (CS-143.1) \\
\hline Methadone & 1358.9 (863.6-2191.4) & 2.1 & 17.3 & 80.6 & $8.69 \quad(8.00-9.41)$ & \\
\hline \multicolumn{7}{|c|}{$\begin{array}{l}\text { Equalize mortality in methadone } \\
\text { state to mortality in diacetylmorphine } \\
\text { state (using diacetylmorphine } \\
\text { estimates) }\end{array}$} \\
\hline Diacetylmorphine & $1091.2(721.5-1703.7)$ & 9.3 & 14.1 & 76.6 & 7.89 (7.29-8.53) & CS (CS-115.4) \\
\hline Methadone & $1118.1(724.7-1758.9)$ & 2.1 & 16.7 & 81.2 & $7.35 \quad(6.86-7.87)$ & \\
\hline \multicolumn{7}{|c|}{$\begin{array}{l}\text { Mortality estimates from } \\
\text { Grönbladh et al. }{ }^{36}\end{array}$} \\
\hline Diacetylmorphine & $941.2(640.8-1435.4)$ & 10.3 & 13.5 & 76.2 & $7.33 \quad(6.65-8.01)$ & 44.8 (CS-146.6) \\
\hline Methadone & $904.2(604.4-1377.4)$ & 2.4 & 16.2 & 81.4 & $6.50 \quad(6.09-6.90)$ & \\
\hline
\end{tabular}


Table 3: Results of sensitivity analyses of the cost-effectiveness of diacetylmorphine compared with methadone in the treatment of refractory opioid dependence over a lifetime horizon (part 2 of 2)

\begin{tabular}{|c|c|c|c|c|c|c|}
\hline \multirow[b]{2}{*}{ Analysis; treatment } & \multirow[b]{2}{*}{$\begin{array}{l}\text { Cost, Can } \$ \times 1000 \\
\text { mean }(95 \% \mathrm{Cl})\end{array}$} & \multicolumn{3}{|c|}{ Cost component, $\%$ total } & \multirow[b]{2}{*}{$\begin{array}{c}\text { QALYs, } \\
\text { mean }(95 \% \mathrm{Cl})\end{array}$} & \multirow{2}{*}{$\begin{array}{c}\text { Incremental } \\
\text { cost-effectiveness ratio, } \\
\text { Can } \$ \times 1000 \text { per QALY } \\
\text { gained, mean }(95 \% \mathrm{CI})\end{array}$} \\
\hline & & Treatment & $\begin{array}{l}\text { Health } \\
\text { resources } \\
\text { utilization }\end{array}$ & $\begin{array}{l}\text { Criminal } \\
\text { activity and } \\
\text { charges }\end{array}$ & & \\
\hline \multicolumn{7}{|c|}{ Treatment starting age $\mathbf{3 0} \mathbf{~ y r}$} \\
\hline Diacetylmorphine & $1292.7(966.5-1736.6)$ & 9.5 & 13.1 & 77.4 & $10.27 \quad(9.69-10.85)$ & CS (CS-123.1) \\
\hline Methadone & $1345.1(965.5-1852.2)$ & 2.2 & 15.3 & 82.5 & $9.83(9.27-10.38)$ & \\
\hline \multicolumn{7}{|c|}{ Treatment starting age $\mathbf{5 0}$ yr } \\
\hline Diacetylmorphine & $840.7(421.7-1653.9)$ & 9.4 & 15.1 & 75.4 & $5.37 \quad(4.82-5.94)$ & CS (CS-148.3) \\
\hline Methadone & $864.3(420.4-1754.2)$ & 2.1 & 18.3 & 79.6 & $4.92(4.40-5.46)$ & \\
\hline \multicolumn{7}{|c|}{$\begin{array}{l}\text { Treatment-specific cost } \\
\text { and utilities }\end{array}$} \\
\hline Diacetylmorphine & $1109.3(712.1-1754.0)$ & 9.3 & 13.1 & 77.6 & $7.99 \quad(7.41-8.60)$ & CS (CS-417.3) \\
\hline Methadone & $1229.2(790.0-1838.1)$ & 2.0 & 15.8 & 82.2 & 7.38 (6.81-7.98) & \\
\hline \multicolumn{7}{|c|}{$\begin{array}{l}\text { No improvement in health- } \\
\text { related quality of life from } \\
\text { treatment to abstinence }\end{array}$} \\
\hline Diacetylmorphine & $1096.1(724.1-1707.2)$ & 9.3 & 14.1 & 76.7 & $7.90 \quad(7.28-8.52)$ & CS (CS-131.3) \\
\hline Methadone & $1137.6(736.8-1776.5)$ & 2.1 & 16.7 & 81.2 & $7.46 \quad(6.90-8.01)$ & \\
\hline
\end{tabular}

crimes committed was not modelled explicitly, because uncertainty on the probability of incarceration and delays in adjudication and sentencing made attribution of these costs to specific health states in the timeframe of the North American Opiate Medication Initiative impossible without strong assumptions. Because rates of crime with and without charges were higher among participants during relapse than during other health states, and because the methadone cohort spent proportionately more time in relapse, omitting these costs favoured methadone maintenance treatment.

Third, because of a high baseline prevalence of hepatitis $\mathrm{C}$ virus infection and a paucity of data on which to base time-variant estimates of costs and consequences associated with this condition, we did not model hepatitis $\mathrm{C}$ seroconversion explicitly. The costs and QALY losses associated with transmission of HIV and hepatitis C virus from infected individuals to the broader population were also not modelled explicitly. Because the probability of seroconversion and transmission of either disease is higher during periods of relapse, these omissions underestimate the incremental cost savings and QALYs gained with diacetylmorphine.

Finally, gains in productivity were not incorporated into our study, because employment outcomes in the North American Opiate Medication Initiative did not show any significant changes in either treatment arm (unemployment rate $71.2 \%$ at baseline and $71.7 \%$ at 12 months).

\section{Conclusion}

Using mathematical modelling to extrapolate results from the North American Opiate Medication Initiative, we found that a treatment strategy featuring diacetylmorphine may be more effective and less costly than methadone maintenance treatment among people with chronic opioid dependence refractory to treatment. Our model indicated that diacetylmorphine would decrease societal costs, largely by reducing costs associated with crime, and would increase both the duration and quality of life of treatment recipients.

\section{References}

1. Amato L, Davoli M, Perucci CA, et al. An overview of systematic reviews of the effectiveness of opiate maintenance therapies: available evidence to inform clinical practice and research. J Subst Abuse Treat 2005;28:321-9.

2. Mattick RP, Kimber J, Breen C, et al. Buprenorphine maintenance versus placebo or methadone maintenance for opioid dependence. Cochrane Database Syst Rev 2008;CD002207.

3. Burns L, Randall D, Hall WD, et al. Opioid agonist pharmacotherapy in New South Wales from 1985 to 2006: patient characteristics and patterns and predictors of treatment retention. Addiction 2009;104:1363-72.

4. Clausen T, Anchersen K, Waal H. Mortality prior to, during and after opioid maintenance treatment (OMT): a national prospective cross-registry study. Drug Alcohol Depend 2008;94:151-7.

5. Hall W. Methadone maintenance treatment as a crime control measure [letter]. BMJ 1996:312:1162.

6. Caplehorn JRM, Dalton MSYN, Cluff MC, et al. Retention in methadone maintenance and heroin addicts' risk of death. Addiction 1994;89:203-9.

7. Degenhardt L, Randall D, Hall W, et al. Mortality among clients 
of a state-wide opioid pharmacotherapy program over 20 years: risk factors and lives saved. Drug Alcohol Depend 2009;105:9-15.

8. Bell J, Burrell T, Indig D, et al. Cycling in and out of treatment; participation in methadone treatment in NSW, 1990-2002. Drug Alcohol Depend 2006;81:55-61.

9. Galai N, Safaeian M, Vlahov D, et al.; ALIVE Study. Longitudinal patterns of drug injection behaviour in the ALIVE study cohort, 1988-2000: description and determinants. Am J Epidemiol 2003;158:695-704

10. Dobler-Mikola A, Hattenschwiller J, Meili D, et al. Patterns of heroin, cocaine and alcohol abuse during long-term methadone maintenance treatment. J Subst Abuse Treat 2005;29:259-65.

11. Bovasso G, Cacciola J. The long-term outcomes of drug use by methadone maintenance patients. J Behav Health Serv Res 2003;30:290-303.

12. Termorshuizen F, Krol A, Prins M, et al. Prediction of relapse to frequent heroin use and the role of methadone prescription: an analysis of the Amsterdam Cohort Study among drug users. Drug Alcohol Depend 2005;79:231-40.

13. Hser YI, Longshore D, Anglin MD. The life course perspective on drug use: a conceptual framework for understanding drug use trajectories. Eval Rev 2007;31:515-47.

14. Johnson RE, Chutuape MA, Strain EC, et al. A comparison of levomethadyl acetate, buprenorphine, and methadone for opioid dependence. N Engl J Med 2000;343:1290-7.

15. Oviedo-Joekes E, Brissette S, Marsh DC, et al. Diacetylmorphine versus methadone for the treatment of opioid addiction. N Engl J Med 2009;361:777-86.

16. Best practices in methadone maintenance treatment. Ottawa $(\mathrm{ON})$ : Health Canada; 2002.

17. Perneger TV, Giner F, del Rio M, et al. Randomised trial of heroin maintenance programme for addicts who fail in conventional drug treatments. $B M J$ 1998;317:13-8.

18. van den Brink W, Hendriks VM, Blanken P, et al. Medical prescription of heroin to treatment resistant heroin addicts: two randomised controlled trials. BMJ 2003;327:310.

19. Haasen C, Verthein U, Degkwitz P, et al. Heroin-assisted treatment for opioid dependence: randomised controlled trial. $\mathrm{Br} \mathrm{J}$ Psychiatry 2007;191:55-62.

20. Strang J, Metrebian N, Lintzeris N, et al. Supervised injectable heroin or injectable methadone versus optimised oral methadone as treatment for chronic heroin addicts in England after persistent failure in orthodox treatment (RIOTT): a randomised trial. Lancet 2010;375:1885-95.

21. Dijkgraaf MGW, van der Zanden BP, de Borgie CAJM, et al Cost utility analysis of co-prescribed heroin compared with methadone maintenance treatment in heroin addicts in two randomized trials. BMJ 2005;330:1297-302.

22. March JC, Oviedo-Joekes E, Perea-Milla E, et al. Controlled trial of prescribed heroin in the treatment of opioid addiction. J Subst Abuse Treat 2006;31:203-11.

23. Oviedo-Joekes E, Nosyk B, Marsh DC, et al. Scientific and political challenges in North America's first randomized controlled trial of heroin-assisted treatment for severe heroin addiction: rationale and design of the NAOMI study. Clin Trials 2009; 6:261-71.

24. Billingham LJ, Abrams KR, Jones DR. Methods for the analysis of quality-of-life and survival data in health technology assessment. Health Technol Assess 1999;3:1-152.

25. Canadian Agency for Drug and Technologies in Health. Guidelines for the economic evaluation of health technologies. Ottawa (ON): The Agency; 2006. Available: http://cadth.ca/media /pdf/186_EconomicGuidelines_e.pdf (accessed 2010 Jan. 31).

26. Sculpher M, Fenwick E, Claxton K. Assessing quality in decision analytic cost-effectiveness models. Pharmacoeconomics 2000; 17:461-77.

27. Ramsey S, Willke R, Briggs A, et al. Good research practices for cost-effectiveness analysis alongside clinical trials: the ISPOR RCT-CEA Task Force report. Value Health 2005;8:521-33.

28. Oviedo-Joekes E, Nosyk B, Brissette S, et al. The North American Opiate Medication Initiative (NAOMI): profile of participants in North America's first trial of heroin-assisted treatment J Urban Health 2008;85:812-25.

29. Briggs A, Sculpher M, Claxton K. Decision modelling for health economic evaluation. New York (NY): Oxford University Press; 2006. p. 45-76

30. Hawkins N, Sculpher M, Epstein D. Cost-effectiveness analysis of treatments for chronic disease: using $\mathrm{R}$ to incorporate time dependency of treatment response. Med Decis Making 2005;25: 511-9.

31. Nosyk B, MacNab YC, Sun H, et al. Proportional hazards frailty models for recurrent methadone maintenance treatment. Am J Epidemiol 2009; 170:783-92.

32. Life tables, Canada, provinces and territories, British Colum bia: 2000-2002. Table no. 84-537-XIE. Ottawa (ON): Statistics Canada. Available: www.statcan.gc.ca/bsolc/olc-cel/olc-cel?lang =eng\&catno=84-537-X (accessed 2012 Feb. 16).

33. Spittal PM, Hogg RS, Li K, et al. Drastic elevations in mortality among female injection drug users in a Canadian setting. AIDS Care 2006; $18: 101-8$

34. Rehm J, Frick U, Hartwig C, et al. Mortality in heroin-assisted treatment in Switzerland 1994-2000. Drug Alcohol Depend 2005;79:137-43

35. Bargagli AM, Hickman M, Davoli M, et al.; COSMO European Group. Drug-related mortality and its impact on adult mortality in eight European countries. Eur J Public Health 2006;16:198202

36. Grönbladh L, Ohlund LS, Gunne LM. Mortality in heroin addiction: impact of methadone treatment. Acta Psychiatr Scand 1990;82:223-7.

37. Zaric GS, Barnett PG, Brandeau ML. HIV transmission and the cost-effectiveness of methadone maintenance. Am J Public Health 2000;90:1100-11.

38. Bayoumi AM, Zaric GS. The cost-effectiveness of Vancouver's supervised injection facility. CMAJ 2008;179:1143-51.

39. Euroqol Group. Euroqol - a new facility for the measurement of health-related quality of life. Health Policy 1990;16:199-208.

40. Brooks R. EuroQol: the current state of play. Health Policy 1996;37:53-72

41. Shaw JW, Johnson JA, Coons SJ. US valuation of the EQ-5D health states: development and testing of the D1 valuation model. Med Care 2005;43:203-20.

42. Nosyk B, Sun H, Guh D, et al. The quality of eight health status measures were compared for chronic opioid dependence. J Clin Epidemiol 2010;63:1132-44

43. Drummond MF, Sculpher MJ, Torrance GW, et al. Methods for the economic evaluation of health care programmes. 3rd ed. New York (NY): Oxford University Press; 2005.

44. Rehm J, Gschwend P, Steffen T, et al. Feasibility, safety, and efficacy of injectable heroin prescription for refractory opioid addicts: a follow-up study. Lancet 2001;358:1417-23.

45. Antiretroviral Therapy Cohort Collaboration, Zwahlen M, Harris $\mathrm{R}$, et al. Mortality of HIV-infected patients starting potent antiretroviral therapy: comparison with the general population in nine industrialized countries. Int J Epidemiol 2009;38:1624-33.

46. Johnson JA, Pickard AS. Comparison of the EQ-5D and SF-12 health surveys in a general population survey in Alberta, Canada. Med Care 2000;38:115-21.

47. Anis AH, Nosyk B, Sun H, et al.; OPTIMA Team. Quality of life of patients with advanced HIV/AIDS: measuring the impact of both AIDS-defining events and non-AIDS serious adverse events. J Acquir Immune Defic Syndr 2009;51:631-9.

48. Wood E, Montaner JS, Tyndall MW, et al. Prevalence and correlates of untreated human immunodeficiency virus type 1 infection among persons who have died in the era of modern antiretroviral therapy. J Infect Dis 2003;188:1164-70.

49. Krentz HB, Auld MC, Gill MJ. The changing direct costs of medical care for patients with HIV/AIDS, 1995-2001. CMAJ 2003;169:106-10.

50. Butt AA, McGinnis KA, Skanderson M, et al. Hepatitis C treatment completion rates in routine clinical care. Liver Int 2010; 30:240-50.

51. National consensus development panel on effective medical treatment of opiate addiction. Effective medical treatment of opiate addiction. JAMA 1998;280:1936-43.

52. Kimber J, Copeland L, Hickman M, et al. Survival and cessation in injecting drug users: prospective observational study of outcomes and effect of opiate substitution treatment. BMJ 2010; 341:c3172.

Affiliations: From the Centre for Health Evaluation and Outcome Sciences (Nosyk, Guh, Bansback, Oviedo-Joekes, Meikleham, Schechter, Anis), Vancouver, BC; the School of Population and Public Health (Oviedo-Joekes, Anis), University of British Columbia, Vancouver, BC; the Department of Medicine, Université de Montréal (Brissette), Montréal, Que.; and the Northern Ontario School of Medicine (Marsh), Sudbury, Ont.

Contributors: Bohdan Nosyk was responsible for the study concept and design, performed the statistical analysis, informed the mathematical analysis and prepared the manuscript. Daphne Guh informed the study design, performed the statistical analysis, informed the mathematical analysis and critically revised the manuscript. Nicholas Bansback informed the study design and mathematical analysis and critically 
revised the manuscript. Aslam Anis informed the study design and critically revised the manuscript. Evan Miekleham led the mathematical analysis. Eugenia Oviedo-Joekes, David Marsh, Suzanne Brissette, Aslam Anis and Martin Schechter were responsible for the design of the North American Opiate Medication Initiative and aided in the design of the economic analysis. All of the authors contributed to the critical revision of the manuscript and approved the final manuscript submitted for publication. Bohdan Nosyk had full access to all of the data in the study and takes responsibility for the integrity of the data and the accuracy of the data analysis.

Funding: The North American Opiate Medication Initiative was supported by grants from the Canadian Institutes of Health Research, the Canada Foundation for Innovation, the Canada Research Chairs Program, the University of British Columbia, Providence Health Care, Université de Montréal, Centre de recherche et d'aide pour narcomanes, the Government of Que- bec, Vancouver Coastal Health and the BC Centre for Disease Control. The sponsors had no role in the design and conduct of the study; the preparation, review and approval of the manuscript; or the decision to submit this manuscript for publication.

Acknowledgements: We acknowledge the assistance of Huiying Sun, Xu Wang and Stephanie Harvard. We thank Nancy Laliberté, Candice Gartry, Paul-André Guevremont, Pascal Schneeberger, Jill Chettiar, Kurt Lock, Jeff Lawlor, Paul Pelletier, Sidney Maynard, Scott MacDonald, Trevor Corneil, Josie Geller, Salima Jutha, Shirley Chai, Mirek Piacsezny, Sonia Sizto, many other staff members, and members of the data and safety monitoring board (including Nady ElGuebaly, Janet Raboud and David Roy) for their dedication; the many Canadian and US scientists who contributed to the early design discussions but ultimately were unable to participate in the trial; and the trial participants in the North American Opiate Medication Initiative. 